\title{
Slip casting of barium zirconate aqueous concentrated suspensions
}

\author{
F. Boschini ${ }^{\text {a }}$, B. Guillaume ${ }^{\text {a }}$, A. Rulmont ${ }^{\mathrm{a}}$, R. Cloots ${ }^{\mathrm{a}}$, R. Moreno ${ }^{\mathrm{b}, *}$ \\ ${ }^{a}$ Laboratoire de Chimie Inorganique Structurale, Department of Chemistry, University of Liège, B-4000 Liège, Belgium \\ ${ }^{\mathrm{b}}$ Instituto de Cerámica y Vidrio, CSIC, c/Kelsen, 5, Cantoblanco, E-28049 Madrid, Spain
}

Received 29 December 2004; received in revised form 4 March 2005; accepted 19 March 2005

Available online 9 June 2005

\begin{abstract}
The rheological behaviour of aqueous suspensions of barium zirconate was studied focusing on the effect of the volume fraction of particles, leading to the determination of the maximum packing fraction. Optimised suspensions dispersed with both polymethacrylic acid and tetramethylammonium hydroxide were slip cast on plaster moulds to produce discs and crucibles, leading to relative green densities greater than $62 \%$ of theoretical ones. Densification was studied at temperatures ranging from 1450 to $1700{ }^{\circ} \mathrm{C}$ by static and dynamic sintering experiments. Scanning electron microscopy studies demonstrate that slip cast parts are dense and very homogeneous, without any significant processing-related defects or abnormal grain growth.
\end{abstract}

(C) 2005 Elsevier Ltd. All rights reserved.

Keywords: Suspensions; Slip casting; Sintering; $\mathrm{BaZrO}_{3}$

\section{Introduction}

Barium zirconate $\left(\mathrm{BaZrO}_{3}\right)$ is used in the manufacturing process of crucibles suitable for the synthesis of single crystals high temperature, superconductors, because of its high resistance to chemical attack by highly corrosive molten phases. ${ }^{1,2}$ Barium zirconate powders have been produced by several synthesis routes, such as the citrate route or the oxalate route, but studies concerning the processing of such powders are scarce. The development of low-cost shaping methods for obtaining homogeneous, defect-free barium zirconate parts is in focus. These requirements are satisfied to a great extent by colloidal forming methods by controlling the interaction forces among the particles dispersed in a liquid phase. ${ }^{3}$

Both the colloidal stability and shape forming of barium titanate suspensions have been extensively investigated, either in water or in non aqueous media. ${ }^{4-11}$ Barium titanate ceramics are used as capacitor for microelectronics. As a consequence, a big effort has been made to produce barium titanate thick-films by tape casting. ${ }^{12,13}$ Moreover, a wide range of dispersants such as sulfonic acid, ${ }^{12}$

\footnotetext{
* Corresponding author.
}

polyvinyl alcohol, ${ }^{14}$ ammonium polymethacrylate and polymethacrylic acid, ${ }^{15-17}$ have been successfully used to stabilize barium titanate suspensions in different solvent systems.

Barium zirconate is mentioned in several reviews dealing with superconductor science as a possible buffer layer for making superconductor cables. It has been recently demonstrated that $\mathrm{BaZrO}_{3}$ nanoparticles can be added to $\mathrm{YBCO}$ as pinning centres to increase the current density in superconducting film. ${ }^{18}$ Furthermore, barium zirconate doped with yttrium on the $\mathrm{Zr}$ sites could be used as a high temperature proton conductor. ${ }^{19,20}$ Thus, doped barium zirconate could soon find interesting applications in fuel cell technology also.

Most of the open literature concerning barium zirconate deals with its synthesis, either by reaction between barium carbonate and zirconia or through the use of precursors (sol-gel, etc.). To the knowledge of the authors, very scarce information is available regarding the powder processing of barium zirconate powders. Although the use of barium zirconate crucibles for superconductors has been reported elsewhere, ${ }^{21-23}$ there are no commercially available crucibles in the market which can resist the corrosive $\mathrm{BaO}-\mathrm{CuO}$ flux for a few days. The density of the crucible and the powder purity are probably the main factors to be controlled 
for obtaining barium zirconate crucibles with good chemical properties.

Considering the emerging applications of barium zirconate, it seems necessary to make some effort to study its shape forming as a fundamental step for manufacturing pieces as crucibles focusing on their sinterability. A basic knowledge concerning the behaviour of barium zirconate particles in water and further shape forming could be used as a starting point for future studies on zirconate ceramics, such as magnesium zirconate, which could be used for melting metals, or calcium zirconate, in electronic applications.

In a previous work, the colloidal stability of aqueous suspensions of barium zirconate has been reported. ${ }^{24}$ It was demonstrated that the behaviour of barium zirconate in water is very similar to that of barium titanate. The variation of zeta potential as a consequence of changing the $\mathrm{pH}$ and the concentration of an anionic polyelectrolyte was studied, the isoelectric point occurring at $\mathrm{pH}$ 5.3. Rheological studies showed that the optimum dispersing conditions were reached for suspensions prepared at basic $\mathrm{pH}$ with $1.5 \mathrm{wt} . \%$ tetramethylammonium hydroxide (TMAH) and a concentration of ammonium polymethacrylate (PMAA) ranging from 1.0 to $1.6 \mathrm{wt} . \%$.

The aim of this work is to optimise the solid loading of the well-dispersed suspensions in order to produce dense and homogeneous bodies of barium zirconate by a slip casting route. In addition to slip optimisation, the sintering conditions are studied, as well as the microstructure of the sintered specimens.

\section{Experimental}

A commercial barium zirconate powder (Alfa Aesar, 99\% purity) produced by solid state reaction between $\mathrm{BaCO}_{3}$ and $\mathrm{ZrO}_{2}$ was used. This powder had specific surface area (BET) of $3.5 \mathrm{~m}^{2} \mathrm{~g}^{-1}$ and average particle size around $1.5 \mu \mathrm{m}$. The chemical analysis of the powder reveals that it is poor in $\mathrm{Ba}$, with a $\mathrm{Ba} / \mathrm{Zr}$ ratio equal to 0.97 . For this study, the starting powder was milled with a planetary mill with zirconia balls to reach an average particle size around $0.5 \mu \mathrm{m}$ and a surface area (BET) of $11.2 \mathrm{~m}^{2} \mathrm{~g}^{-1}$. The density of the powder measured by He-picnometry was around $6.0 \mathrm{~g} \mathrm{~cm}^{-3}$, significantly lower than the theoretical density $\left(6.23 \mathrm{~g} \mathrm{~cm}^{-3}\right)$.

An ammonium polymethacrylate (PMAA, Dolapix CE 64, Zschimmer \& Schwarz, Germany) was used as the deflocculant agent. This deflocculant is supplied as a solution with a concentration of active matter of $35 \%$. Concentrations are expressed as weight $\%$ (wt.\%), referred to the solid loading of the as-received product. Basicity was provided with tetramethylammonium hydroxide (TMAH), expressed also as wt.\% of as-received product, referred to the solid loading of ceramic powder. According to previous results, the concentration of TMAH was fixed to $1.5 \mathrm{wt} . \%$, while two concentrations of PMAA were tested, 1.0 and $1.6 \mathrm{wt} . \%$.
Suspensions with solid contents of $29,40,45$, and $50 \mathrm{vol} . \%$ (i.e. $72,80,84$ and 86 wt.\%) were dispersed with a highenergy ultrasonic probe (IKA 400S, Germany) for $1 \mathrm{~min}$ and stirred for $20 \mathrm{~h}$ before any measurement in order to establish an equilibrium dispersion system.

The rheological behaviour of all studied slips was determined using a rheometer (Haake RS50, Karlsruhe, Germany) operating at both controlled shear rate (CR) and controlled shear stress (CS) conditions. The first mode was used to measure the flow curves, and the second mode for determining the yield values, calculated from the double logarithmic plots of deformation versus shear stress. The measurements were performed at a constant temperature of $25^{\circ} \mathrm{C}$ using a double cone and plate system, with a solvent trap. Values of viscosity extrapolated to zero and infinite shear rates were calculated using the Cross model on flow curves measured at CS and $\mathrm{CR}$ mode, respectively. The maximum packing fraction of the suspensions was estimated by using the Krieger-Dougherty model with the calculated limit viscosities.

Studied suspensions were slip cast on plaster of Paris moulds to obtain both solid discs $(2 \mathrm{~cm}$ in diameter) and crucibles. The density of the green bodies was measured by mercury immersion after drying for $48 \mathrm{~h}$ at room temperature and the values are reported as \% of the theoretical density of $\mathrm{BaZrO}_{3}\left(6.23 \mathrm{~g} \mathrm{~cm}^{-3}\right)$.

Dynamic sintering studies were performed with a differential dilatometer (Adamel Lhomargy, DI24, France). For static sintering tests, green specimens were treated at temperatures ranging from 1450 to $1700^{\circ} \mathrm{C}$ using a heating rate of $10^{\circ} \mathrm{C} \mathrm{min}^{-1}$ and soaking time of $2 \mathrm{~h}$. Sintered densities were measured by Archimedes' method in water. Scanning electron microscopy (ESEM, Philips XL 30, Germany) was used for microstructural observations done on both polished and thermally etched surfaces and fracture surfaces. Chemical analysis was performed by EDX (ESEM, Philips XL 30, Germany).

\section{Results and discussion}

\subsection{Rheological characterisation}

The effect of solid loading on the rheological behaviour of aqueous suspensions of barium zirconate was studied in order to determine the better slip casting performances. Fig. 1 shows the flow curves measured at CR mode of suspensions prepared with solid loadings of $29,40,45$, and 50 vol. $\%$ and deflocculated with $1.5 \mathrm{wt} . \%$ TMAH and $1.0 \mathrm{wt} . \%$ PMAA. The corresponding CR flow curves obtained with $1.6 \mathrm{wt} . \%$ PMAA are plotted in Fig. 2 for comparison.

In a first approximation, apparent yield points were calculated from CS measurements as the intercepting point of the two straight lines registered in the log-log plot of strain versus stress, while thixotropy was calculated from the CR curves. Table 1 summarises the main rheological parameters of those suspensions. All the suspensions were slip cast and 


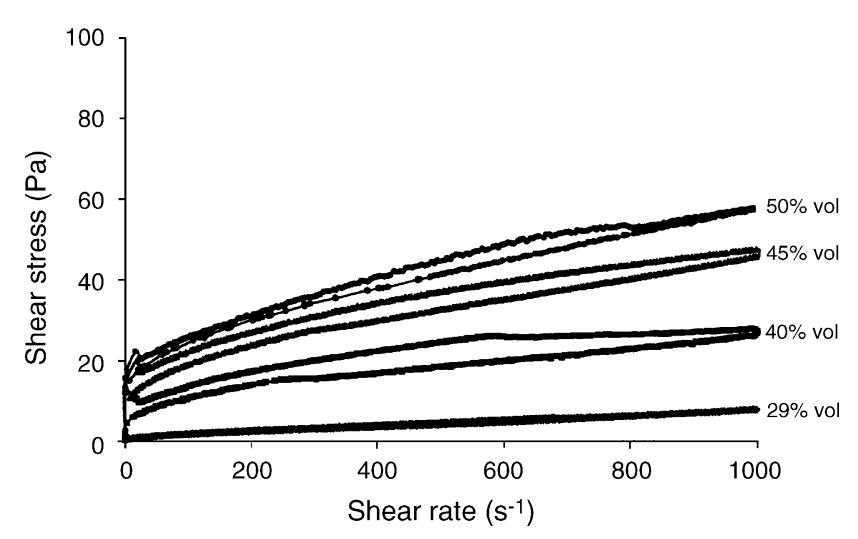

Fig. 1. CR flow curves of suspensions with $1.5 \mathrm{wt} . \%$ of TMAH and $1.0 \mathrm{wt} . \%$ of polyelectrolyte prepared to different solids loading.

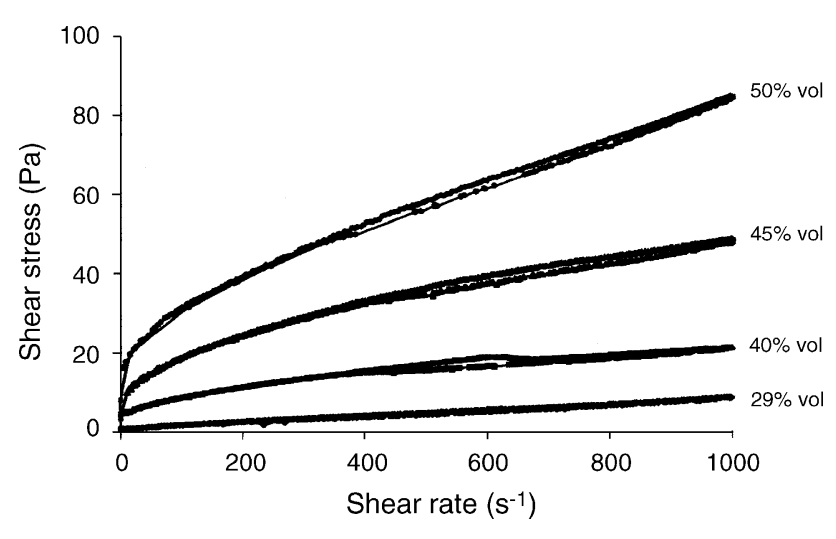

Fig. 2. CR flow curves of suspensions with $1.5 \mathrm{wt} . \%$ of TMAH and $1.6 \mathrm{wt} . \%$ of polyelectrolyte prepared to different solids loading.

the resulting green densities are also reported in Table 1. It must be noticed that suspensions with 50 vol.\% solids are too concentrated to obtain reliable rheological measurements (values in brackets in Table 1), as they tend to dry rapidly. Hence, this solid loading is not appropriate for slip casting.

For suspensions with $1.0 \mathrm{wt} . \%$ PMAA, the relative density increases with solid loading. Suspensions with $1.6 \mathrm{wt} . \%$ PMAA lead to larger relative densities than those with $1.0 \mathrm{wt} . \%$ and do not depend on solid loading. However, the large differences in the relative densities could not be explained from the small differences in the rheological properties. It was experimentally observed that these slips showed

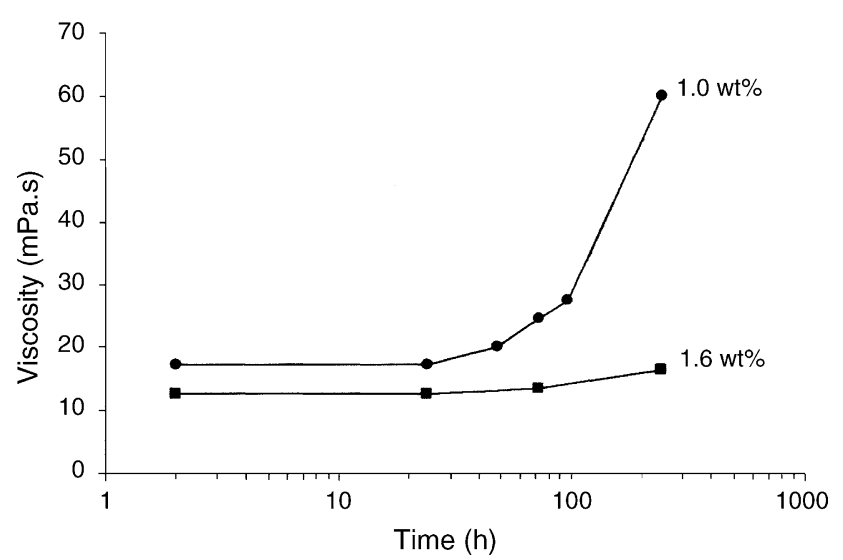

Fig. 3. Evolution of viscosity with ageing time for suspensions with $1.5 \mathrm{wt} . \%$ of TMAH with 1.0 and $1.6 \mathrm{wt}$. $\%$ of polyelectrolyte $(\phi=0.29)$.

Table 2

Extrapolated values of viscosity of optimised $\mathrm{BaZrO}_{3}$ suspensions

\begin{tabular}{lrc}
\hline$\phi$ & $\eta_{0}(\mathrm{mPas})$ & $\eta_{\infty}(\mathrm{mPas})$ \\
\hline 0.29 & $4.7 \times 10^{3}$ & 7.1 \\
0.40 & $2.7 \times 10^{6}$ & 10.4 \\
0.45 & $54.8 \times 10^{6}$ & 22.7 \\
0.50 & $133.9 \times 10^{6}$ & 44.9 \\
\hline
\end{tabular}

a significant ageing effect. For this reason, the effect of ageing time on the viscosity was studied for suspensions with 1.0 and 1.6 wt.\% PMAA. For such a study the lowest solid loading was selected (i.e. 29 vol. $\%$ ), where a lower ageing time dependence is expected. Fig. 3 plots the variation of viscosity with ageing time for both suspensions. Suspensions with $1.0 \mathrm{wt}$.\% PMAA have a low viscosity for ageing times up to $24 \mathrm{~h}$ but viscosity increases with ageing time and becomes unstable after 3 days. For $1.6 \mathrm{wt} . \%$ of PMAA the suspension maintains its stability over 10 days, demonstrating that an excess of polyelectrolyte is needed in order to preserve the stability of the suspensions against time.

This preliminary characterization demonstrates that the best dispersing conditions for slip casting are reached by adding $1.6 \mathrm{wt} . \%$ polyelectrolyte. These conditions were selected for further work.

After this preliminary rheological characterization, in which the existence of an apparent yield stress is assumed,

Table 1

Rheological parameters of $\mathrm{BaZrO}_{3}$ suspensions with different volume fractions

\begin{tabular}{|c|c|c|c|c|c|c|c|c|}
\hline \multirow[t]{3}{*}{$\phi$} & \multicolumn{8}{|c|}{ PMAA wt. $\%$} \\
\hline & \multicolumn{2}{|c|}{ Yield stress $(\mathrm{Pa})$} & \multicolumn{2}{|c|}{ Thixotropy $\left(\mathrm{Pa} \mathrm{s}^{-1}\right)$} & \multicolumn{2}{|c|}{$\eta$ at $100 \mathrm{~s}^{-1}(\mathrm{mPas})$} & \multicolumn{2}{|c|}{ Green density $(\% \mathrm{TD})$} \\
\hline & 1.0 & 1.6 & 1.0 & 1.6 & 1.0 & 1.6 & 1.0 & 1.6 \\
\hline 0.29 & 0.4 & 0.4 & 525 & 388 & 18.6 & 17.2 & 55.9 & 61 \\
\hline 0.40 & 10.0 & 2.8 & 4411 & 755 & 136 & 83 & 56.8 & 62.2 \\
\hline 0.45 & 22.5 & 4.8 & 3836 & 1555 & 227 & 184 & 57.7 & 59.7 \\
\hline 0.50 & 30.3 & 14.4 & 2606 & $(412)$ & 262 & (309) & 60.1 & 62.2 \\
\hline
\end{tabular}




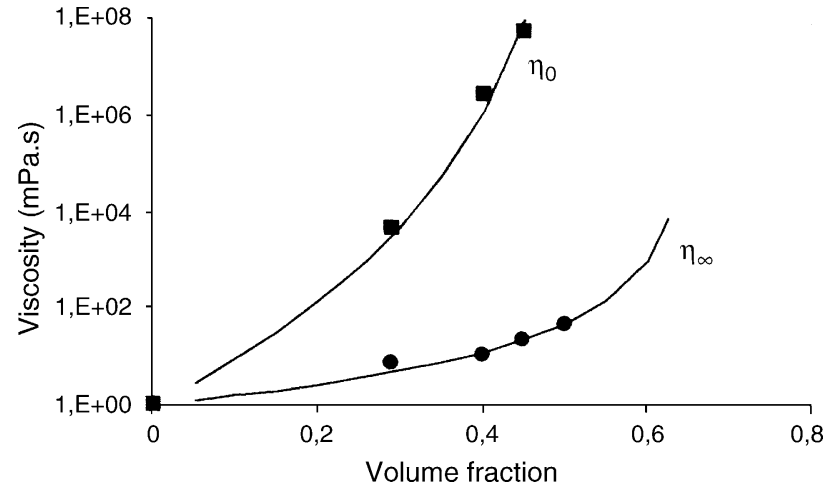

Fig. 4. Variation of viscosity values extrapolated to zero and infinite shear rate with volume fraction of particles, and fitting to the Krieger-Dougherty model.

a deeper analysis was made for predicting the general shape of a flow (or viscosity) curve using a regression model that differentiates both extreme shear regions. In this work, experimental data were fitted to the Cross model, which assumes that there is no a real yield stress, but the viscosity at rest has

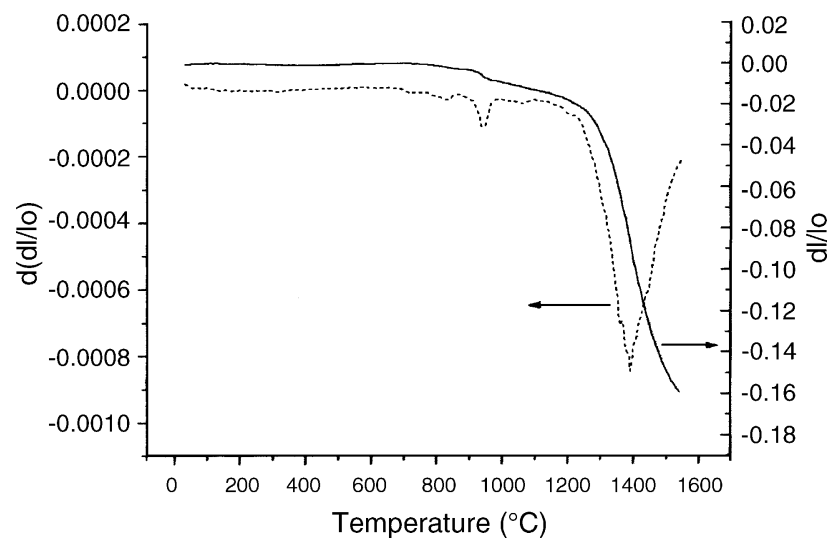

Fig. 5. Dynamic sintering curves of $\mathrm{BaZrO}_{3}$ compacts produced by slip casting.

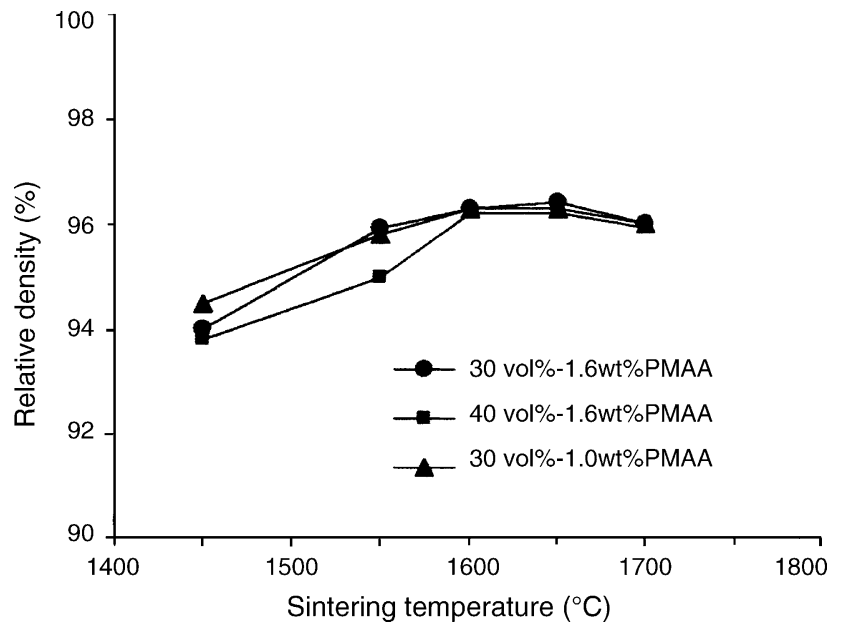

Fig. 6. Variation of relative density of slip cast $\mathrm{BaZrO}_{3}$ compacts as a function of sintering temperature. a finite value

$$
\frac{\eta_{0}-\eta}{\eta-\eta_{\infty}}=(k \dot{\gamma})^{m}
$$

In this equation, $\eta_{0}$ is the extrapolation of the viscosity to a zero shear rate and is referred to as zero shear viscosity, $\eta_{\infty}$ is the limit viscosity extrapolated to infinite shear rate, $k$ is a constant with dimensions of time and $m$ is a dimensionless
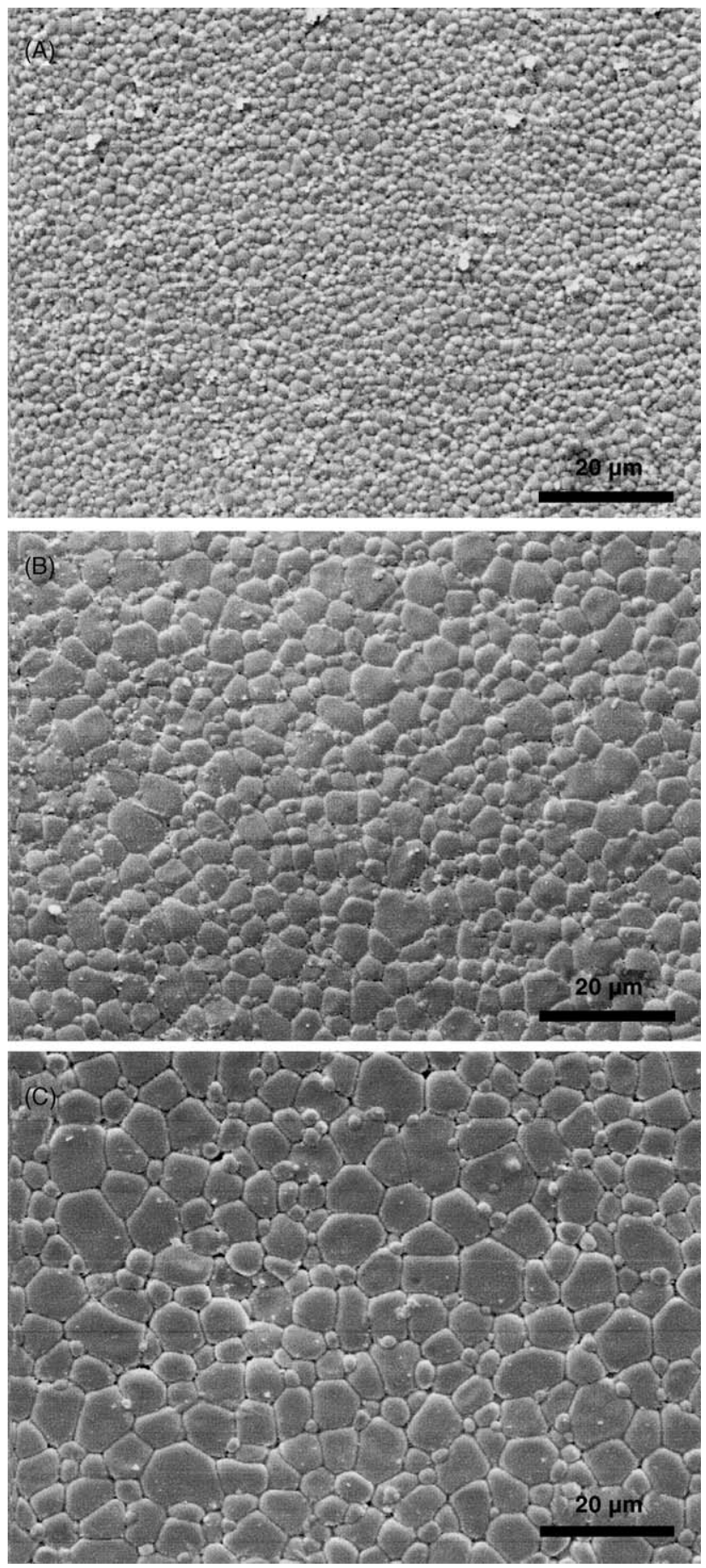

Fig. 7. ESEM microstructure of slip cast $\mathrm{BaZrO}_{3}$ surfaces sintered at $1450^{\circ} \mathrm{C}(\mathrm{A}), 1600^{\circ} \mathrm{C}(\mathrm{B})$, and $1700^{\circ} \mathrm{C}(\mathrm{C})$. 
constant. Table 2 reports the Cross model parameters of the suspensions prepared at different solid loading. Values of $\eta_{0}$ were obtained by fitting the CS curve toward zero shear, while values of $\eta_{\infty}$ were obtained by fitting the high shear region with CR curves.

When the solid content increases, the viscosity increases, but there is a maximum concentration of particles for which viscosity tends to infinity, indicating that a compact structural network has been formed. This concentration defines the maximum packing fraction $\left(\phi_{\mathrm{m}}\right)$. It can be calculated using the Krieger-Dougherty model by introducing the intrinsic viscosity $[\eta]$, which has a typical value of 2.5 for suspensions of spherical particles:

$\eta=\eta_{\mathrm{s}}\left(1-\frac{\phi}{\phi_{\mathrm{m}}}\right)^{-[\eta] \phi_{\mathrm{m}}}$

where $\eta_{\mathrm{s}}$ is the viscosity of the dispersing medium. To predict the evolution of viscosity with solid fraction in slurries with non-spherical particles the exponent factor $[\eta] \phi_{\mathrm{m}}$ is commonly replaced by an exponent $n$, referred to a so-called modified Krieger-Dougherty model. Fig. 4 shows the variation of $\eta_{0}$ and $\eta_{\infty}$ calculated according to the Cross model as a function of the volume fraction. The experimental
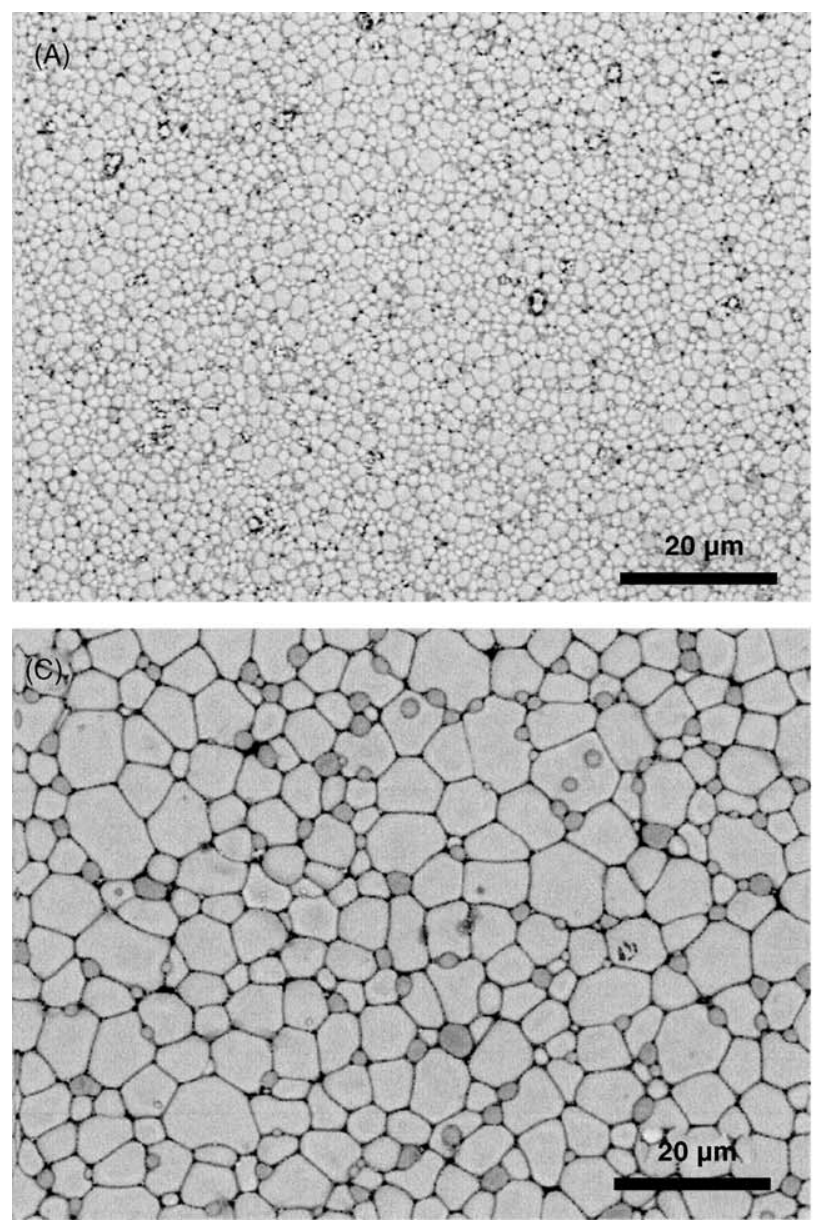

data can be adequately fitted in both the high shear and the low shear regions, but the results are very different in each region. The Krieger-Dougherty model was developed from the Einstein's theory for diluted suspensions, which are mainly dominated by viscous flow. Hence, the high shear rate region better represents the intrinsic viscosity $\left(\eta_{\infty}\right)$. The intrinsic viscosity calculated for the high shear region is $[\eta]=4$, considerably higher than the value of 2.5 predicted by Einstein, because the particles are not perfectly spherical and monodispersed. The application of the Krieger-Dougherty model provides a maximum packing fraction of 0.53 in the zero-shear region and 0.64 in the high shear region, which is in the range of the measured values of the relative green density $(>62 \%)$, thus demonstrating that this model fits better the values of $\eta_{\infty}$.

\subsection{Sintering}

The shrinkage behaviour has been studied by means of high temperature dilatometry. Fig. 5 shows the dynamic sintering curves for a $\mathrm{BaZrO}_{3}$ specimen obtained by slip casting using a 40 vol.\% suspension. The shrinkage curves show three different regions at different temperatures: below
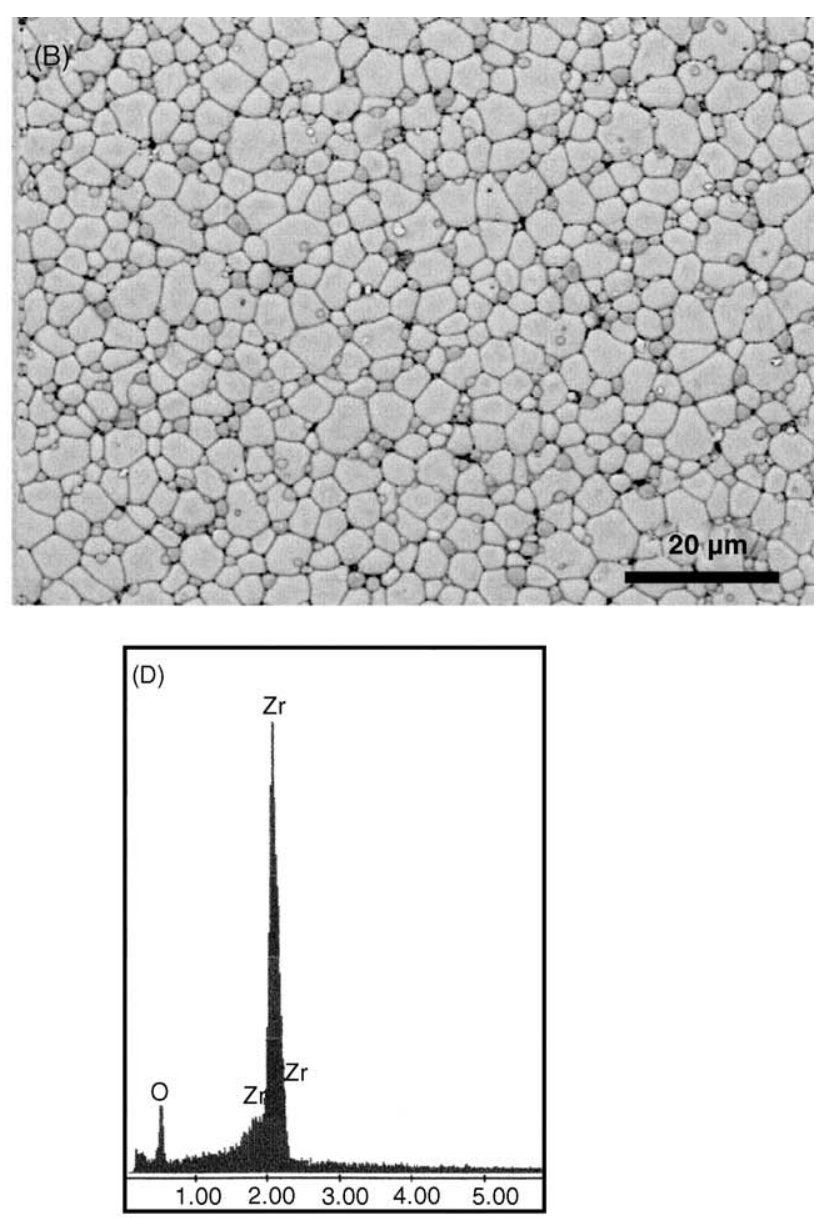

Fig. 8. ESEM pictures taken in the $\mathrm{BSE}$ mode of slip cast $\mathrm{BaZrO}_{3}$ surfaces sintered at $1450{ }^{\circ} \mathrm{C}(\mathrm{A}), 1600^{\circ} \mathrm{C}(\mathrm{B})$, and $1700^{\circ} \mathrm{C}(\mathrm{C})$, and $\mathrm{EDX}$ spectrum of small dark particles observed in the BSE pictures of Fig. 8. 
$800^{\circ} \mathrm{C}$, between 800 and $1250^{\circ} \mathrm{C}$ and above $1250^{\circ} \mathrm{C}$. Below $800^{\circ} \mathrm{C}$ no shrinkage is observed. The onset of shrinkage starts around $800{ }^{\circ} \mathrm{C}$ up to $1250^{\circ} \mathrm{C}$, where sintering necks start to develop. Above $1250^{\circ} \mathrm{C}$, a large increase of the densification rate occurs with a maximum densification rate at $\sim 1400^{\circ} \mathrm{C}$.

Static sintering tests were performed using green slip cast samples obtained from suspensions with $1.6 \mathrm{wt} . \%$ PMAA prepared with solid loading of 29 and $40 \mathrm{vol} . \%$, since higher contents did not provide better densities and lead to difficult pourability of the slips into the moulds. Samples were sintered at temperatures of $1450,1550,1600$, 1650 , and $1700^{\circ} \mathrm{C}$, with heating rates of $10^{\circ} \mathrm{C} \mathrm{min}^{-1}$ and $2 \mathrm{~h}$ soaking. Fig. 6 plots the relative density of sintered parts as a function of sintering temperature. The densification is already effective for a temperature around $1450^{\circ} \mathrm{C}$, where a relative density of $94 \%$ is reached, thus confirming the results provided by dilatometric measurements. A maximum relative density of $96.5 \%$ is obtained between 1600 and $1650^{\circ} \mathrm{C}$ for all the samples. Therefore, the densification of $\mathrm{BaZrO}_{3}$ up to $97 \%$ of the theoretical density needs a thermal treatment at high temperature $\left(1700^{\circ} \mathrm{C}\right)$ and long sintering times $(48 \mathrm{~h}) .{ }^{1}$ A slight decrease in the final density can be noticed when isotherm temperature is higher than $1650^{\circ} \mathrm{C}$, which is in agreement with previous studies that relate the lowering density to abnormal grain growth. ${ }^{25}$

Sintering studies were also conducted by ESEM observations. Fig. 7 shows the ESEM microstructure of slip cast bodies obtained from 29 vol.\% suspensions sintered at 1450,1600 , and $1700^{\circ} \mathrm{C}$. As it can be seen the specimens are dense at $1450{ }^{\circ} \mathrm{C}$ and higher temperatures promote coarsening rather than further densification. The microphotographs reveal a very homogeneous microstructure without agglomerates or exaggerated grain growth. Homogeneous coarsening occurs as sintering temperature increases. The appearance of the samples as observed by ESEM indicates that sintered density is greater than that measured by Archimedes' method, this being probably related to the non-stoechiometry of the as-received powder, whose real density is lower than the theoretical one.

Pictures of these samples were also taken in the backscattering mode (BSE). Fig. 8 shows the $\mathrm{BSE}$ pictures of $\mathrm{BaZrO}_{3}$ surfaces fired at 1450,1600 , and $1700^{\circ} \mathrm{C}$ for $2 \mathrm{~h}$. The grain size at each temperature can be better observed than in Fig. 7. In the BSE mode, small dark grains can be observed between large white grains. The composition of these small dark grains was investigated by EDX (Fig. 8D). EDX analysis undoubtely shows that those small dark grains correspond to barium-free zirconia phase, thus proving that the commercial powder used is not stoichiometric but is poor in barium. Some $\mathrm{Zr}$-enrichment must be also a consequence of the milling process.

ESEM observations were also performed on fracture surfaces (Fig. 9), which reveal the presence of some closed pores entrapped at the grain boundaries and located at the triple points.
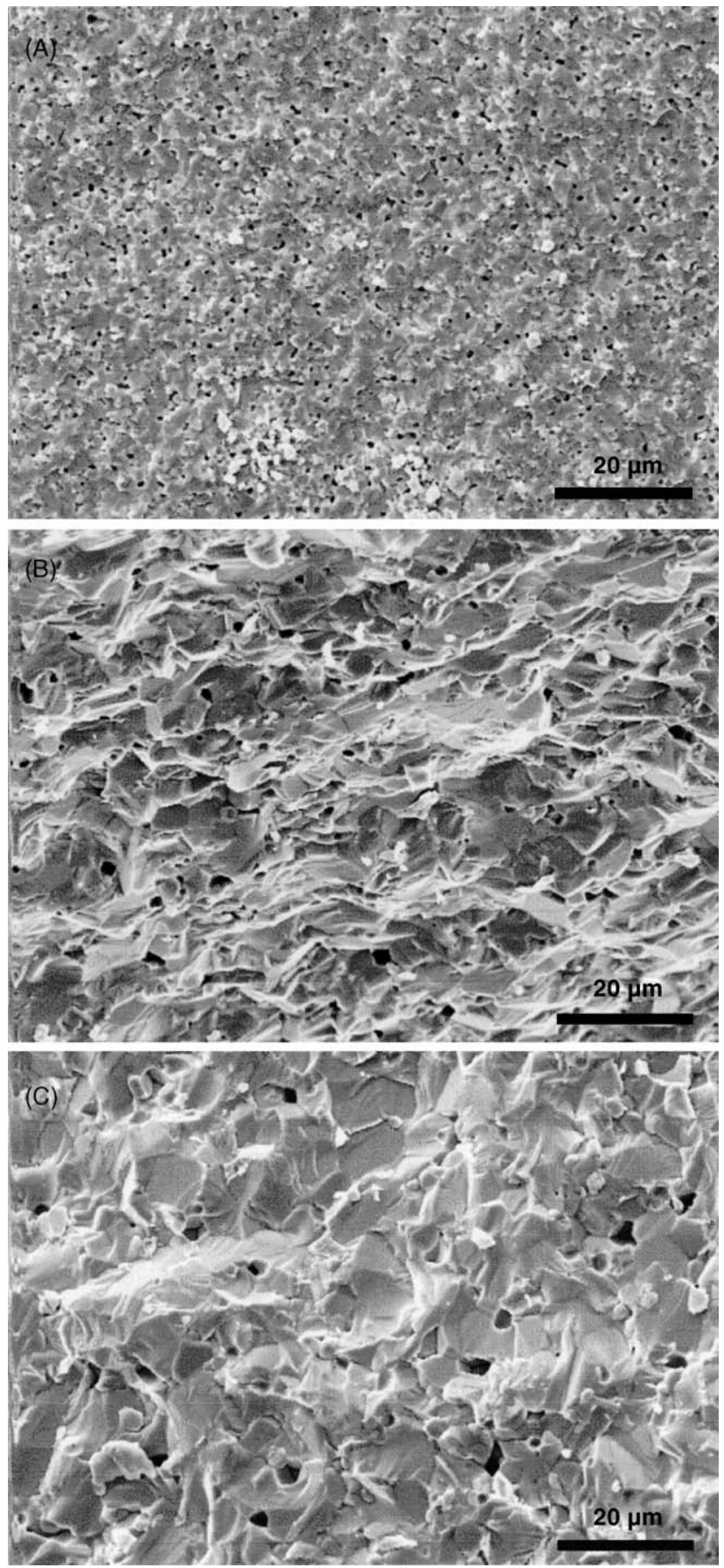

Fig. 9. ESEM fracture surfaces of slip cast $\mathrm{BaZrO}_{3}$ sintered at $1450^{\circ} \mathrm{C}(\mathrm{A})$, $1600^{\circ} \mathrm{C}(\mathrm{B})$, and $1700^{\circ} \mathrm{C}(\mathrm{C})$

These results demonstrate that slip casting is a powerful technique for manufacturing dense barium zirconate parts with a high microstructural uniformity and controlled grain size. To illustrate the feasibility of the optimised shaping procedure, Fig. 10 shows the appearance of $\mathrm{BaZrO}_{3}$ crucibles produced by slip casting using 29 vol. $\%$ suspensions stabilised with $1.5 \mathrm{wt} . \%$ TMAH and $1.6 \mathrm{wt} . \%$ PMAA in the green state (A) and after sintering at $1650{ }^{\circ} \mathrm{C}$ during $2 \mathrm{~h}$ (B). 

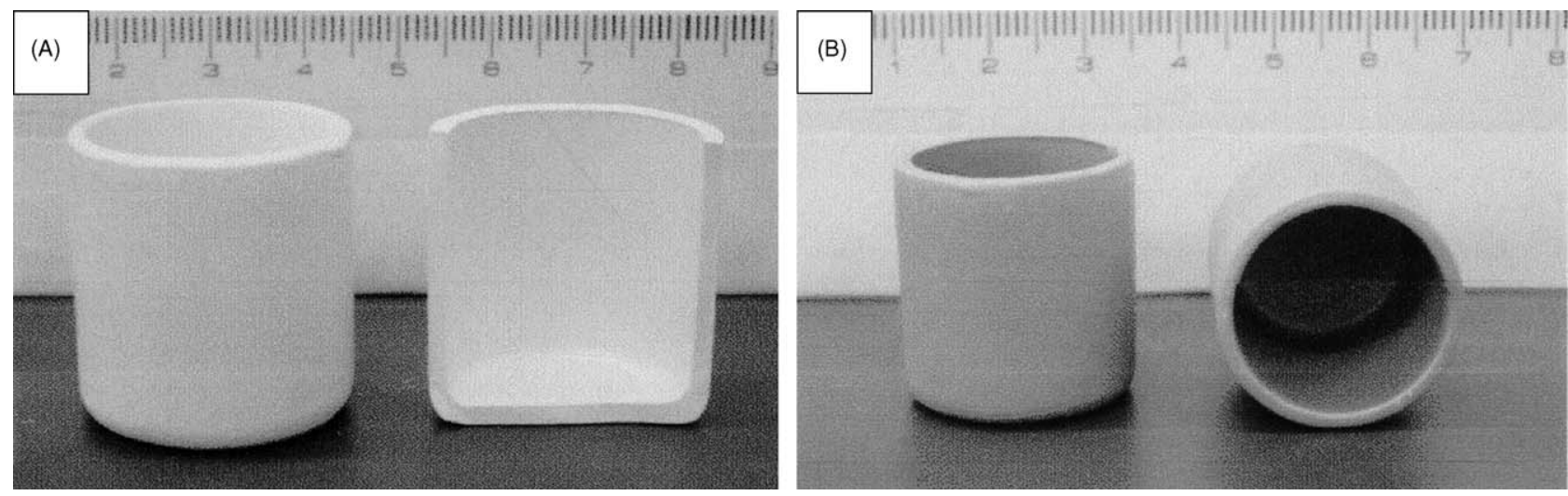

Fig. 10. $\mathrm{BaZrO}_{3}$ crucibles obtained by slip casting in the green state (A) and after sintering at $1650^{\circ} \mathrm{C} / 2 \mathrm{~h}(\mathrm{~B})$.

\section{Conclusions}

Aqueous suspensions of barium zirconate have been prepared in water at solid loadings ranging from 29 to 50 vol.\% by dispersing with $1.6 \mathrm{wt} . \%$ of PMAA as polyelectrolyte and 1.5 wt.\% TMAH. At these conditions, suspensions are stable over 10 days. A maximum packing fraction of 0.64 was determined using the semi-empirical Krieger-Dougherty model. Slip casting of the optimised suspensions led to ceramic parts with relative green density greater than $60 \%$ of the theoretical one. Maximum sintered densities of $96.5 \%$ of TD are obtained for an isothermal temperature around $1650{ }^{\circ} \mathrm{C}$ for $2 \mathrm{~h}$. However, microstructural observations reveal that very homogeneous materials are obtained without abnormal grain growth and free of defects, such as bubbles or agglomerates. EDX analysis reveals the existence of some zirconia grains, thus proving that the commercial powder used is not stoechiometric but is poor in barium. Slip casting allows the manufacturing of defect-free, dense crucibles of barium zirconate.

\section{Acknowledgements}

The FNRS (Belgian National Fund for Scientific Research) and the University of Liège are gratefully acknowledged for financial support. We wish to thank the centre of Microscopy of Liège (CAT $\mu$ ) for its contribution to the powder characterisation by ESEM and EDX. R. Moreno acknowledges CICYT (Spain) for financial support (MAT2003-00836).

\section{References}

1. Erb, A., Walker, E. and Flukiger, R., $\mathrm{BaZrO}_{3}$ : The solution for the crucible corrosion problem during the single crystal growth of highTc superconductors $\mathrm{REBa}_{2} \mathrm{Cu}_{3} \mathrm{O}_{7-\mathrm{x}}: \mathrm{RE}=\mathrm{Y}$. Pr. Phys. C, 1995, 245, 245-251.

2. Zhang, J. L. and Evetts, J. E., $\mathrm{BaZrO}_{3}$ and $\mathrm{BaHfO}_{3}$ : preparation, properties and compatibility with $\mathrm{YBa}_{2} \mathrm{Cu}_{3} \mathrm{O}_{7-\mathrm{x}}$. J. Mater. Sci., 1994, 29, 778-785.
3. Lange, F. F., Powder processing science and technology for increased reliability. J. Am. Ceram. Soc., 1989, 72, 3-15.

4. Blanco-López, Rand, B. and Riley, F. L., The isoelectric point of $\mathrm{BaTiO}_{3}$. J. Eur. Ceram. Soc., 2000, 20, 107-118.

5. Blanco-López, Rand, B. and Riley, F. L., Polymeric stabilisation of aqueous suspensions of barium titanate. Part I: Effect of pH. J. Eur. Ceram. Soc., 2000, 20, 1579-1586.

6. Blanco López, Rand, B. and Riley, F. L., Polymeric stabilisation of aqueous suspensions of barium titanate. Part II: Effect of polyelectrolyte concentration. J. Eur. Ceram. Soc., 2000, 20, 15871594.

7. Anderson, D. A., Adair, J. H., Miller, D., Biggers, J. V. and Shrout, T. R., Surface chemistry effects on ceramic processing of $\mathrm{BaTiO}_{3}$ powder. In Ceramic Transactions, vol. 1. Ceramic Powder Science, II, ed. G. L. Messing, E. R. Fuller and H. Hausner. American Ceramic Society, Westerville, OH, 1988, pp. 485-492.

8. Paik, U., Lee, S. and Hackley, V. A., Influence of barium dissolution on the electrokinetic properties of colloidal $\mathrm{BaTiO}_{3}$ in an aqueous medium. J. Am. Ceram. Soc., 2003, 86, 1662-1668.

9. Mizuta, S., Parish, M. and Bowen, H. K., Dispersion of $\mathrm{BaTiO}_{3}$ powders (Part I). Ceram. Int., 1984, 10, 43-48.

10. Bergström, L., Colloidal processing of a very fine $\mathrm{BaTiO}_{3}$ powderEffect of particle interactions on the suspension properties, consolidation and sintering behavior. J. Am. Ceram. Soc., 1997, 80(2), 291-300.

11. Bzdawka, J. A. and Haworth, D. T., The dispersion of barium titanium oxide in water and methylisobutylketone. J. Dispersion Sci. Techn., 1980, 1(3), 323-340.

12. Pagnoux, C., Chartier, T., Granja, M. de F., Doreau, F., Ferreira, J. M. and Baumard, J. F., Aqueous suspensions for tape-casting based on acrylic binders. J. Eur. Ceram. Soc., 1998, 18, 241-247.

13. Braun, L., Morris J.R.Jr. and Cannon, W. R., Viscosity of tape-casting slips. Am. Ceram. Soc. Bull., 1985, 64(5), 727-729.

14. De Laat, A. W. M. and Derks, W. P. T., Colloidal stabilization of $\mathrm{BaTiO}_{3}$ with poly(vinyl alcohol) in water. Colloids and Surfaces A, 1993, 71, 147-153.

15. Yáñez, C. G., Balmori-Ramírez, H. and Martínez, F., Colloidal processing of $\mathrm{BaTiO}_{3}$ using ammonium polyacrylate as dispersant. Ceram. Int., 2000, 26, 609-616.

16. Jean, J. H. and Wang, H. R., Stabilization of aqueous $\mathrm{BaTiO}_{3}$ suspensions with ammonium salt of poly(acrylic acid) at various $\mathrm{pH}$ values. J. Mater. Res., 1998, 13, 2245-2250.

17. Chen, Z. C., Ring, T. A. and Lemaitre, J., Stabilization and processing of aqueous $\mathrm{BaTiO}_{3}$ suspension with polyacrylic acid. J. Am. Ceram. Soc., 1992, 75(12), 3201-3208.

18. Macmanus-Driscoll, J. L., Foltyn, S. R., Jia, Q. X., Wang, H., Serquis, A., Civale, L., Maiorov, B., Hawley, M. E., Maley, M. P. and Peterson, D. E., Strongly enhance current densities in superconducting coated conductors of $\mathrm{YBa}_{2} \mathrm{Cu}_{3} \mathrm{O}_{7-\mathrm{x}}+\mathrm{BaZrO}_{3}$. Nat Mater, 2004, 3, 439-443. 
19. Bohn, H. G. and Schober, T., Electrical Conductivity of the HighTemperature Proton Conductor $\mathrm{BaZr}_{0,9} \mathrm{Y}_{0,1} \mathrm{O}_{2,95}$. J. Am. Ceram. Soc., 2000, 83, 768-772.

20. Kreuer, K. D., Aspects of the Formation and Mobility of Protonic Charge Carriers and the Stability of Perovskite-Type Oxides. Solid State Ionics, 1999, 125, 285-302.

21. Liang, R., Bonn, D. A. and Hardy, W. N., Growth of High Quality YBCO Single Crystal Using $\mathrm{BaZrO}_{3}$ Crucibles. Physica C, 1998, 304, 105-111.

22. Alford, N. M., Templeton, A. and Penn, S. J., A simple process for manufacturing barium zirconate crucibles. Superconductor Sci. Techn., 1998, 11(7), 703.
23. Morita, Y., Motohashi, T., Sugihara, S. and Yamauchi, H., HighQuality RE-123 Single Crystals Grown in $\mathrm{BaZrO}_{3}$ crucible. Physica C, 2002, 378-381, 360-363.

24. Boschini, F., Rulmont, A., Cloots, R. and Moreno, R., Colloidal stability of aqueous suspensions of barium zirconate. J. Eur. Ceram. Soc., 2005, 25(13), 3195-3201.

25. Guillaume, B., Boschini, F., Garcia-Cano, I., Rulmont, A. and Cloots, $\mathrm{R}$., $\mathrm{BaZrO}_{3}$ sintering process optimization with a precise control of the initial powder size distribution: A factorial design statistical analysis. J. Eur. Ceram. Soc., 2005, 25(16), 3593-3604. 